\title{
Correlação entre doença periodontal e doença respiratória
}

\author{
Correlation between periodontal disease and respiratory disease
}

Correlación entre enfermedad periodontal y enfermedad respiratória

Fernanda Caroline Cardoso dos Santos ${ }^{1 *}$, Rafael De Aguiar Vilela Junior ${ }^{1}$.

\section{RESUMO}

Objetivo: O presente trabalho tem por objetivo fazer uma revisão de literatura sobre a relação entre a doença periodontal e sua influência com a doença respiratória. Métodos: Por meio de revisão de literatura foram pesquisados e selecionados artigos científicos publicados relacionado a doença periodontal e seu envolvimento com a doença respiratória. Desenvolvimento: A doença periodontal decorre, na maioria, em pacientes cuja saúde bucal não é tratada. Ou seja, quando não há um controle preventivo sobre a microbiota presente na cavidade bucal, permitindo assim a entrada de agentes patogênicos e início de processo patológico. As doenças respiratórias são tão frequentes como qualquer outra doença. Por serem bastante comuns, os indivíduos portadores não dão o devido valor e agravam o seu estado de saúde, pois são correlacionadas a maus hábitos, ao clima ou a fatores extrínsecos como vírus e bactérias. É importante a abordagem dessas duas áreas de saúde para um bom conhecimento entre sua correlação no organismo. $O$ início de uma doença respiratória está diretamente ligado ao índice de colonização de patogênicos respiratórios na cavidade bucal e orofaringe devido a sua aspiração pelas vias aéreas inferiores levando o organismo a um estado de mecanismo de defesa do hospedeiro. Considerações finais: A prevenção pelo tratamento odontológico prévio se faz necessário para evitar qualquer futuro agravo a respeito da saúde sistêmica do paciente no caso de doença respiratória e seu envolvimento com a doença periodontal. Por isso, é importante mais estudos a respeito de suas associações para melhor aprimoramento sobre $o$ assunto.

Palavras-Chave: Doença periodontal, Doença respiratória, Associação.

\begin{abstract}
Objective: This study aims to review the literature on the relationship between periodontal disease and its influence on respiratory disease. Methods: Through literature review we searched and selected published scientific articles related to periodontal disease and its involvement with respiratory disease. Development: Periodontal disease occurs mostly in patients whose oral health is not treated. That is, when there is no preventive control over the microbiota present in the oral cavity, thus allowing the entry of pathogens and beginning of pathological process. Respiratory diseases are as frequent as any other disease. Because they are very common, individuals do not give the proper value and worsen their state of health, because they are correlated to bad habits, climate or extrinsic factors such as viruses and bacteria. It is important to approach these two areas of health to a good knowledge among their correlation in the body. The onset of a respiratory disease is directly related to the rate of colonization of respiratory pathogens in the oral cavity and oropharynx due to its aspiration through the lower airways leading the organism to a state of defense mechanism of the host. Final considerations: Prevention by previous dental treatment is necessary to avoid any future grievances regarding the patient's systemic health in case of respiratory disease and its involvement with periodontal disease. Therefore, further studies on their associations are important for better improvement on the subject.
\end{abstract}

Key words: Periodontal disease, Respiratory disease, Association.

${ }^{1}$ Instituto Nacional de Ensino Superior Padre Gervásio (INAPÓS). Pouso Alegre-MG.

*Email: fer_caroline@outlook.com

SUBMETIDO EM: $12 / 2018$

ACEITO EM: 01/2019

PUBLICADO EM: 02/2019 


\section{RESUMEN}

Objetivo: El trabajo tiene por objetivo hacer una revisión de literatura sobre la relación entre la enfermedad periodontal y su influencia con la enfermedad respiratoria. Métodos: Por medio de la revisión de literatura fueron investigados y seleccionados artículos científicos publicados relacionados a enfermedad periodontal y su implicación con la enfermedad respiratoria. Desarrollo: La enfermedad periodontal se deriva,en su mayoría, en pacientes cuya salud bucal no es tratada. Es decir,cuando no hay control preventivo sobre la microbiota presente en la cavidad bucal, permitiendo así la entrada de agentes patógenos e inicio de proceso patológico. Las enfermedades respiratorias son tan frecuentes como cualquier otra enfermedad. Por ser bastante comunes, los individuos portadores no dan el debido valor y agravan su estado de salud, pues están correlacionados a malos hábitos, al clima oa factores extrínsecos como virus y bacterias. Es importante el abordaje de estas dos áreas de salud para un buen conocimiento entre su correlación en el organismo. El inicio de una enfermedad respiratoria está directamente ligado al índice de colonización de patógenos respiratorios en la cavidad bucal y orofaringe debido a su aspiración por las vías aéreas inferiores llevando al organismo a un estado de mecanismo de defensa del huésped. Consideraciones finales: La prevención por el tratamiento odontológico previo se hace necesario para evitar cualquier futuro agravio respecto a la salud sistémica del paciente en el caso de enfermedad respiratoria y su implicación con la enfermedad periodontal. Por eso,es importante más estudios acerca de sus asociaciones para mejor mejoramiento sobre el tema.

Palabras clave: Enfermedad periodontal, Enfermedad respiratoria, Asociación.

\section{INTRODUÇÃO}

A doença periodontal decorre, na maioria, em pacientes cuja saúde bucal não é tratada. Ou seja, quando não há um controle preventivo sobre a microbiota presente na cavidade bucal, permitindo assim a entrada de agentes patogênicos e início de processo patológico (SABA-CHUJFI et al. 2007). A sua prevalência em toda a população mundial é estimada aproximadamente de $90 \%$ de indivíduos que apresentam algum grau da doença (PIHLSTROM et al. 2005).

A doença periodontal (DP) é formada por bactérias gram-negativas causando um estado infeccioso crônico considerada mundialmente como o segundo maior agente causal de patologia dentária na população (PETERSEN; OGAWA, 2005). Esta patologia é estabelecida como uma doença instalada em sitio específico com evolução contínua intercalando com períodos acentuados e de recidiva ocasionado devido a uma resposta imune e inflamatória devido as toxinas liberadas pelas bactérias presentes. A progressão dos tecidos afetados é dada com pela sua característica morfológicas que se diferencia em relação à outras doenças infecciosas (LINDHE; KARRING; LANG, 2003).

A evolução das manifestações clínicas se baseia a partir do caráter agressor dos microrganismos e a resistência do hospedeiro a enfrentar à agressão. Primeiramente um desequilíbrio entre a resistência do hospedeiro e as bactérias é formado causando alterações periodontais e formando um exsudato inflamatório. Inicia-se um processo de alteração da cor da gengiva levando à uma hemorragia e edema podendo ser revertido se a causa for removida (KALDAHL et al. 1996).

As doenças pulmonares também apresentam os microrganismos gram-negativos como etiologia principal, sendo assim liberando toxinas no local em que se encontra podendo causar um estado inflamatório devido à resposta imunológica ativa (MOJON, 2002). Durante muito tempo a cavidade oral foi classificada sendo o local de reservatório de agentes patogênicos respiratórios (SCANNAPIECO; RETHMAN, 2003). O processo infeccioso se dá pela aspiração durante a respiração de patógenos orais que se alojam nos pulmões podendo resultar à uma pneumonia, ou pela colonização de placa bacteriana presentes nos dentes por patógenos respiratórios ou patógenos periodontais aspirados pela via aérea superior (MOJON et al. 1997).

Desse modo, a relação entre essas duas doenças é compreendida em áreas diferentes da saúde, mas acabam sendo bem ligadas sendo que uma poderá gerar a outra. Por isso, é necessário o conhecimento das doenças periodontais como potencial fator de alteração de uma condição sistêmica para uma nova abordagem terapêutica e preventiva (BERNARDON, 2006). 


\section{MÉTODOS}

O presente trabalho trata-se de uma revisão da literatura sendo um método realizado a partir da junção de vários resultados de pesquisa de forma condensada de um tema específico e que tem por finalidade agregar de forma organizada e a temática na atenção da saúde.

Para isso, foram pesquisados e selecionados artigos científico publicados relacionado a doença periodontal e doença respiratória e sua correlação. Utilizou-se fontes bibliográficas em bases de dados como o Scielo, Google Acadêmico e Pubmed. A busca dos artigos incluiu estudos de revisão de literatura, monografias e estudos de relato de casos clínicos.

\section{RESULTADOS E DISCUSSÃO}

\section{Doença periodontal}

A doença periodontal é uma doença infecciosa que desencadeia um processo inflamatório podendo acometer os tecidos de suporte como a gengiva, mas também os tecidos de sustentação tais como o cemento radicular, ligamento periodontal e o osso alveolar dos dentes (ARMITAGE, 1999). Esta patologia se caracteriza pelo seu nível de comprometimento sendo assim, existem estágios de progressão da doença. Pode levar a perda de inserção gengival e do ligamento periodontal bem como destruição dos tecidos ósseos adjacentes. Em casos mais avançados da evolução da doença, se o comprometimento for agressivo, leva-se à perda do elemento dental pela ação das bactérias presentes e acúmulo de tártaro com sua inflamação após formação de bolsas periodontais levando a mobilidade dentária (PIHLSTROM et al. 2005).

A etiologia da doença periodontal é microbiana e seu agravo é por negligência da saúde bucal do indivíduo. O desequilíbrio entre as alterações da flora bacteriana presentes na cavidade oral pela liberação de produtos gerados por eles e a resistência do hospedeiro pela resposta imune pode acarretar à uma infecção oportunista e consequentemente aumentar a severidade da doença (SABA-CHUJFI et al. 2007).

Esta patologia é causada pelas bactérias gram-negativas sendo considerada como a segunda maior causa de patologia dentária na população humana de todo o mundo. Sua evolução é baseada em função do sítio em que se localiza levando a um processo inflamatório como resposta imunológica do organismo contra os agentes agressores, sendo assim a sua progressão é beneficiada dependendo da capacidade de resistência do seu hospedeiro a combater a sua ação (MOJON, 2002).

O primeiro aspecto de mecanismo de defesa se dá pela resposta inflamatória presente sendo caracterizada pela gengivite, onde ocorre um desequilíbrio entre o processo inflamatório levando a alterações vasculares, e o potencial patogênico das bactérias podendo levar à doença periodontal. Portanto, há uma alteração de cor da gengiva demonstrando uma hemorragia, assim como presença de edema, resultando em um estado reversível se a causa for removida. Este processo pode provocar posteriormente pela sua evolução um agravo maior passando sua condição para uma periodontite (KALDAHL et al. 1996).

A resposta imunológica de cada indivíduo é uma peça fundamental para o início e a progressão desta doença. O mecanismo de defesa é acionado assim que é detectado a presença de bactérias específicas no indivíduo, mas é a partir da resposta imune que vai indicar se as lesões ocorrerão em nível celular e tecidual (KORNMAN; PAGE, 2000).

Deste modo, podemos classificar a doença periodontal em função de sua gravidade e estágio de evolução entre Gengivite e Periodontite visto que a primeira é um estágio reversível e a segunda irreversível. É importante ressaltar que nem todas as gengivites evoluem para uma periodontite, mas todas as periodontites passaram por uma gengivite. A diferença entre ambas é que na gengivite devido ao acúmulo de placa bacteriana há uma alteração no complexo vascular gengival demonstrada pelo edema, vermelhidão. Já na periodontite o número de bactérias gram-negativas aumenta e esta é caracterizada pela perda de tecido de suporte causando perda de inserção e osso alveolar (ALMEIDA et al. 2006). 


\section{Doença respiratória}

As doenças respiratórias são tão frequentes como qualquer outra doença podendo atingir o ser humano, sendo algumas mais graves que outras e podendo levar a morte. Por sua vez, estão correlacionadas a maus hábitos, ao clima ou a fatores extrínsecos como vírus e bactérias. Consequentemente, por serem bastante comuns, os indivíduos portadores não dão o devido valor e agravam o seu estado de saúde. Essas enfermidades atacam o sistema respiratório, atingindo os pulmões. Sendo ele responsável pelas trocas de gases com o ar, distribuição de oxigênio no sangue e é necessário para realizar todas as reações químicas do organismo. O sistema respiratório é formado a partir: nariz, cavidade nasal, faringe, laringe, traquéia, brônquios, bronquíolos, alvéolos e por fim os pulmões. Sendo assim, é fundamental para a sobrevida de um indivíduo (BERNARDON, 2006).

Existem várias categorias de fatores intrínsecos e extrínsecos que podem causar uma doença respiratória tais como: Infecções virais gerando muitas infecções que atacam alguns órgãos desse sistema, por exemplo a gripe, as pneumonias, sinusites e rinites; Alérgenos gerado pelas alergias, tal como a poeira, pêlos de animais, ácaros, pólen e mofo; Cigarro (tabaco) ou produtos que possuem o cheiro forte ou fumaça; Medicamentos que possuem efeitos colaterais que desencadeia reações alérgicas; Genética que se torna bastante comuns por algumas doenças serem hereditárias; Poluição que causa má qualidade do ar tem muita influência no índice das doenças respiratórias. As doenças respiratórias que podem acometer os pulmões são as doenças pulmonares obstrutiva crônica (DPOC), bronquite crônica, pneumonia bacteriana, enfisema pulmonar, asma ou câncer de pulmão (Mojon, 2002).

\section{A doença periodontal e doença respiratória}

A medicina periodontal ao longo de vários estudos demonstrou que várias doenças sistêmicas podem interferir no progresso patogênico da doença periodontal. O suposto envolvimento das condições orais de um indivíduo como uma infecção periodontal pode se tornar um fator de risco ou um incentivo para gerar uma complicação sistêmica como uma doença respiratória (BERNARDON, 2006).

O processo inicial de inflamação presente frente às lesões ou infecções como resposta de defesa do hospedeiro caracterizado por edema, dor, vermelhidão, calor pode gerar a liberação de produtos biologicamente ativos tanto na doença periodontal quanto nas doenças respiratórias (ALMEIDA et al. 2006).

É importante a abordagem dessas duas áreas de saúde para um bom conhecimento entre sua correlação no organismo. O início de uma doença respiratória está diretamente ligado ao índice de colonização de patogênicos respiratórios na cavidade bucal e orofaringe devido a sua aspiração pelas vias aéreas inferiores levando o organismo a um estado de mecanismo de defesa do hospedeiro (BERNARDON, 2006).

A doença periodontal e a doença respiratória apresentam os microrganismos anaeróbios gram negativos como etiologia, portanto gera-se a liberação de substâncias biológicas ativas que causa uma resposta imunológica e inflamatória. A cavidade bucal por si própria é um reservatório de bactérias respiratórias que podem ser aspiradas ainda mais se este indivíduo apresenta uma saúde bucal deficiente por não controlar através de odontologia preventiva a microbiota bucal patogênica responsável pelo início da doença periodontal (MOJON, 2002).

A infecção pode ser adquirida por meio de aspiração dos patógenos orais levando estes ao pulmão podendo causar pneumonia, aspiração dos patógenos presentes na placa dentária bacteriana que está se encontra no indivíduo ou pela facilidade de colonização de patógenos na via aérea superior (MOJON et al. 1997). A microbiota da bactéria presente em indivíduo que não apresenta doença periodontal se difere daquela que apresenta a patologia em razão da falta de higiene oral e possíveis infeções tais como a gengivite e a periodontite. Por este motivo, há maior prevalência de infecções em pacientes idosos entre eles, os que não tem condição em procurar tratamento odontológico, devido a baixa imunidade e ao alto nível de microrganismos com potencial patogênico na cavidade oral e que são aspirados pelas vias aéreas (SCANNAPIECO e RETHMAN, 2003). 


\section{CONSIDERAÇÕES FINAIS}

A partir dessa revisão de literatura conclui-se que é de grande importância estudar e conhecer a correlação direta entre a doença periodontal e respiratória pois são ambas as patologias que apresenta um alto potencial de morbidade e mortalidade na população mundial. Alguns estudos demonstram que existe uma associação entre ambas, porém ainda deve-se investigar mais sobre o assunto com novos estudos para ter um conhecimento claro e conclusivo. Vale ressaltar que a prevenção pelo tratamento odontológico prévio se faz necessário para evitar qualquer futuro agravo a respeito da saúde sistêmica do paciente.

\section{REFERÊNCIAS}

1. ALMEIDA RF, et al. Associação entre doença periodontal e patologias sistémicas. Rev Port Clin Geral 2006;22:379-90.

2. BERNARDON MA. Estudo da associação entre periodontite e doença pulmonar: levantamento epidemiológico [dissertação]. Passo Fundo: Hospital São Vicente de Paulo de Passo Fundo; 2006.

3. KALDAHL WB, et al. Long-term evaluation of periodontal therapy I: response to 4 therapeutic modalities. J Periodontol 1996 Feb;67(2):93-102.

4. LINDHE J, et al. Clinical periodontology and implant dentistry. 4th edition. Copenhagen: Blakwell Munskgaard; 2003.

5. MARIOTTI A. A primer on inflammation. Compend Contin Educ Dent. 2004;25(7 Suppl 1):7-15.

6. MACEDO FR, et al. Associação entre periodontite e doença pulmonar. RGO, Porto Alegre, v. 58, n.1, p. 47-53, jan./mar. 2010.

7. MOJON $\mathrm{P}$, et al. Oral health and history of respiratory tract infection in frail institutionalised elders. Gerodontology. 1997;14(1):9-16.

8. MOJON P. Oral health and respiratory infection. J Can Dent Assoc. 2002;68(6):340-5.

9. PETERSEN PE, OGAWA H. Strengthening the prevention of periodontal disease: the WHO approach. J Periodontol 2005 Dec; 76(12):2187-93.

10. PIHLSTROM BL,et al. Periodontal diseases. Lancet 366(9499):1809- 1820.

11. SABA-CHUJFI E, et al. Medicina periodontal: uma visão integrada. In: Ottoni J. Cirurgias plásticas periodontais e periimplantares. São Paulo: Santos; 2007. p.241- 83.

12. SCANNAPIECO FA, RETHMAN MP. The relationship between periodontal diseases and respiratory diseases. Dent Today. 2003;22(8):79-83. 